\title{
Impact of Urban Rail Transit Network on Residential and Commercial Land Values in China: A Complex Network Perspective
}

\author{
Shiping Wen, ${ }^{1}$ Jiangang Shi, ${ }^{2}$ and Wei Zhang ${ }^{3}{ }^{3}$ \\ ${ }^{1}$ School of Civil Engineering and Architecture, Chongqing University of Science and Technology, Chongqing 401331, China \\ ${ }^{2}$ School of Economics and Management, Tongji University, Shanghai 201804, China \\ ${ }^{3}$ School of Public Administration, Sichuan University, Chengdu, Sichuan 610065, China
}

Correspondence should be addressed to Wei Zhang; zhangwei2017@mail.ccnu.edu.cn

Received 15 September 2020; Revised 15 September 2020; Accepted 24 April 2021; Published 3 May 2021

Academic Editor: Ali Minai

Copyright (C) 2021 Shiping Wen et al. This is an open access article distributed under the Creative Commons Attribution License, which permits unrestricted use, distribution, and reproduction in any medium, provided the original work is properly cited.

Urban rail transit can improve a city's accessibility. However, high construction and operation costs restrict the development of urban rail transit. Value capture recoups the additional value that the investments of urban rail transit confer to local land and is considered to be an effective measure to alleviate this financial problem. Understanding the land value uplift effects of urban rail transit is essential for understanding value capture. This study applied a Space-P model of urban rail transit network based on complex network theory and demonstrated the influence of urban rail transit network characteristics on residential and commercial land prices. The model was tested with eight metropolises in China, using the 2003 to 2022 timeframe as the context. The results showed a significant positive correlation between the number of nodes and the land prices, the average clustering coefficient was highly positively correlated with the land prices, and there was a significant negative correlation between the average path length and the land prices. This study provides theoretical support for value capture, is beneficial for urban rail transit planning, and supports improvements in the development quality of urban rail transit networks.

\section{Introduction}

Urban rail transit increases the supply of public transportation and has significant external effects [1]. Therefore, many countries and regions have been willing to develop urban rail transit. However, the construction cost of rail transit increases each year. The average construction cost per kilometer was more than RMB 700 million in China in 2018. The operating costs are also high, and most urban rail transit project investments face significant deficits. As a local public good, the construction funds for urban rail transit mostly depend on financial expenditures by the local government [2]. With the rapid development of urban rail transit, the question of funding is becoming increasingly problematic and is a major constraint for developing urban rail transit.

To alleviate the capital problem and find an alternative option of funding urban rail transit, scholars have proposed the method of value capture and have conducted many studies about the relationship between urban rail transit and land value uplift. The effects of urban rail transit on land value vary based on the different land types, land policies, the distance from stations, the passenger flow, and the urban rail transit construction period $[3,4]$. Some studies show that urban rail transit can promote land value uplift [5], while others support the opposite view $[6,7]$.

Most studies have focused on the impact of urban rail transit lines or stations on the surrounding land value at the micro level. However, few studies have estimated the influence of urban rail transit on land value by regarding the urban rail transit system as a complex network at the macro level.

To fill these research gaps, this study introduced complex network analysis to establish an urban rail transit network Space-P model and applied mathematical modeling and 
empirical research methods to demonstrate the impact of urban rail transit network characteristics on residential and commercial land prices at the macro and dynamic level. The objective of the study was to analyze the influence of the network global characteristics of the urban rail transit network Space-P model on the prices of residential and commercial land and to evaluate the land value uplift effects of an urban rail transit network.

By introducing complex network theory, this study provides a new research perspective on how urban rail transit networks influence increases in land value, provides a theoretical reference for policymakers related to land value capture, supports urban rail transit planning, and provides insights for enhancing competitiveness of urban rail transit.

\section{Literature Review}

2.1. The Influence of Urban Rail Transit on Property Values. The mainstream literature has reported that urban rail transit has led to positive land value appreciation [5, 8-10]; however, some studies have demonstrated negative effects, such as noise, air pollution, and an increase in crime near stations $[6,7]$. The effect of urban rail transit on property value has spatial heterogeneity, with the location being the main factor that influences the property value $[11,12]$. Real estates located near rail transit stations experience the largest price effect [13-15]. It is generally believed that the greatest impacts occur within a 10-minute walking distance or within a half-mile of rail transit stations [3, 16]. Urban rail transit impacts suburbs more than the city center [17], and low-income people are considered the beneficiaries of urban rail transit [18]. The operation of urban rail transit can improve housing prices in residential areas for lowincome people; however, it has no significant influence or negative effect in residential areas for high-income people [19-21].

The land values associated with different land-use types are affected by urban rail transit to different degrees [22]. Urban rail transit has a significant impact on commercial and residential land. It promotes the development of commercial and residential land along the line and can increase commercial and residential land prices. In contrast, it has a negative effect on industrial land [15, 23-27]. Commercial land prices are $12 \%$ higher than residential land prices within a quarter of a mile from rail transit stations [28].

The effects on land prices are different in different construction periods of urban rail transit. In the early stage of construction, the impact on land price is not significant before the government announces funding source information [29]. However, once the government announces the source of funds, the land value uplift induced by urban rail transit peaks. During the urban rail transit construction period, the land value uplift gradually decreases [30]. Diao et al. [31] found that residential land value uplift reached its peak one year before the opening of urban rail transit and then gradually decreases.

There has been a significant discussion about the relationship between urban rail transit and land value uplift. However, most studies have analyzed the effects of specific stations or local characteristics of urban rail transit on property prices along the line, focusing at the micro level. As such, little is known about the effects of the urban rail transit system on land value uplift from a complex network perspective.

2.2. Value Capture. Urban rail transit improves accessibility, reduces transportation costs, and shortens travel time. The public is willing to pay higher costs to live and work near urban rail transit stations, which has somewhat contributed to land value uplift [32]. Alonso [33], Muth [34], and Mills [35] have proposed that the land value uplift caused by improved accessibility and decreased transportation costs should be separated from property values. The land value uplift created by urban rail transit investments belongs to the public and should be captured [36].

Mechanisms such as Public-Private Partnerships (PPP) and Build-Operate-Transfers (BOT) can somewhat alleviate capital shortages during infrastructure construction; however, the dependence of construction costs on the government has remained unchanged [37]. Value capture supports the balancing of revenues and expenditures for urban rail transit investments and restrains the excessive consumption of infrastructure and the overexploitation of land $[38,39]$. Value capture can be facilitated through such tools as land taxes, land increment taxes, and property taxes $[40,41]$. Joint development and land taxes are two common methods for value capture [42]. To formulate and implement value capture policies, however, it is important to assess the impact of urban rail transit on land value uplift $[30,43]$.

\section{Methods}

\subsection{Complex Network Analysis}

3.1.1. Urban Rail Transit Network. As a kind of technical network in society, the urban rail transit system has the characteristics of a complex network and, as such, can be abstracted for network analysis. In the urban rail transit network, the nodes represent the stations, and the edges reflect the connectivity between the stations [44]. The main methods used to establish a complex network model are Space-L, Space-B, Space-P, and Space-C. Of these, the Space-P model is one of the most common methods for establishing a transportation network [45], as it can highlight the traffic transfer information for an urban rail transit system. Each line in the urban rail transit system constitutes a subgraph of the Space-P model, and the nodes connecting different subgraphs represent transfer stations.

In the Space-P model of an urban rail transit network, if two stations are on the same line (that is, they can reach each other without transferring to other lines), then an edge is added between the two stations. Using a simple graph with six stations and two lines as an example, depicted in Figure 1(a), the yellow line consists of the stations A, B, C, and $\mathrm{D}$; the purple line is composed of the stations $\mathrm{E}, \mathrm{B}, \mathrm{C}$, and $\mathrm{F}$; and the stations $\mathrm{B}$ and $\mathrm{C}$ are two transfer stations. Then, the complex network constructed by the Space- $P$ method is shown in Figure 1(b). The urban rail transit 


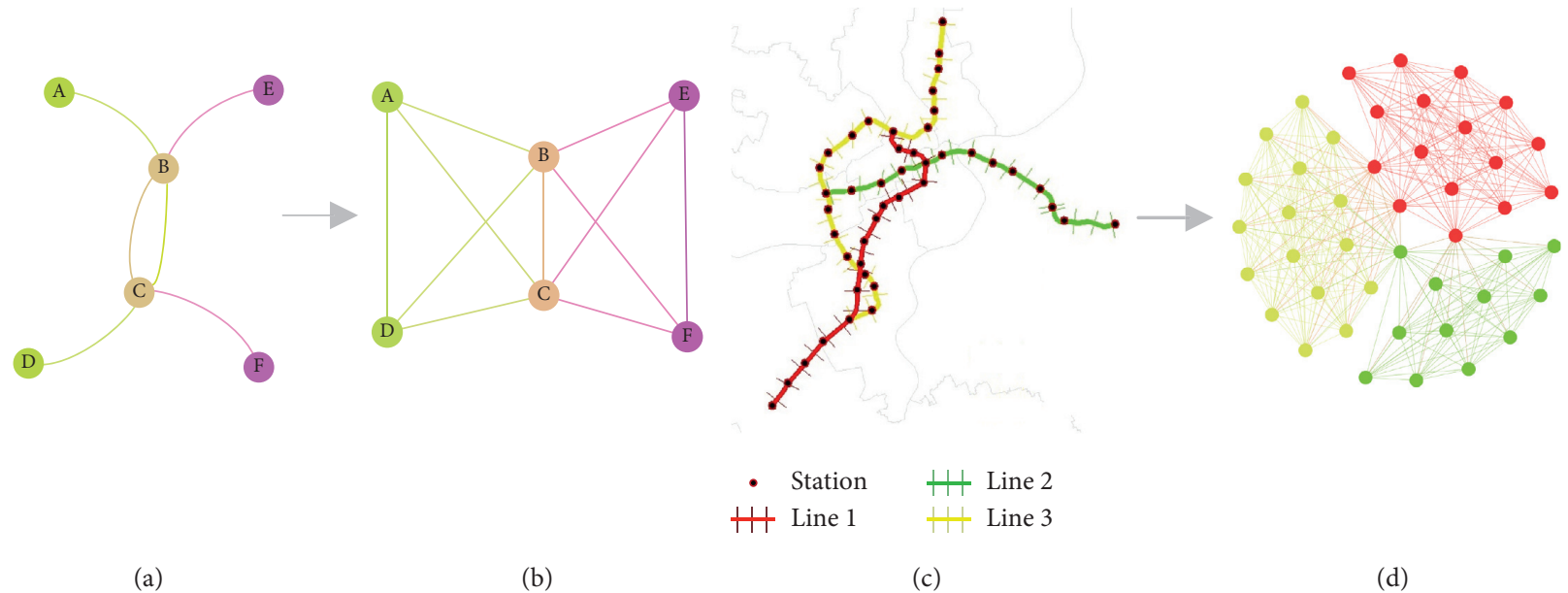

Figure 1: The method used to establish the Space-P model for urban rail transit.

system in Shanghai in the year 2000 is shown as an example in Figure 1(c). The system contains three lines: line 1 (red line), line 2 (green line), and line 3 (yellow line). There are 44 stations, including four transfer stations. Figure 1(d) shows the Space-P model of the urban rail transit network in Shanghai in 2000, with 44 nodes and 368 edges. An edge exists between any two stations on the same line in the Space-P model.

3.1.2. Network Characteristics. The number of nodes, the number of edges, average clustering coefficient, and average path length were selected to measure the global network characteristics of the urban rail transit Space-P model.

In the model, the number of nodes and the number of edges are the two most direct indicators of network size, represented by $n$ and $e$, respectively. The number of nodes equals the number of urban rail transit network stations. There is an edge connection between any two stations on the same line; as such, there are a large number of edges in the urban rail transit Space-P network. The clustering coefficient of a node refers to the ratio of the number of edges between all nodes adjacent to the node to the maximum possible number of edges between adjacent nodes. The clustering coefficient of node $v_{i}$ is expressed as

$$
c_{i}=\frac{e_{i}^{\prime}}{k_{i}\left(k_{i}-1\right) / 2} \text {. }
$$

The variable $k_{i}$ is the degree of node $v_{i}$; that is, there are $k_{i}$ nodes adjacent to node $v_{i} ; e_{i}^{\prime}$ is the number of edges between all nodes adjacent to node $v_{i}$; the maximum possible value of the number of edges between adjacent nodes is $k_{i}\left(k_{i}-1\right) / 2$.

The average clustering coefficient refers to the average clustering coefficient of all nodes in a complex network. Most of the nodes have a higher clustering coefficient in the urban rail transit Space-P model. As such, the average clustering coefficient is larger, and the network has a higher degree of tight connection. The average clustering coefficient is described as

$$
c=\frac{1}{n} \sum_{i=1}^{n} c_{i}
$$

The average path length is the average of the shortest path length between any two nodes in a complex network. The values reflect the average number of routes between any two stations along the shortest path. The average shortest path length of urban rail transit Space-P network is relatively small. The average path length is described as

$$
l=\frac{1}{n(n-1) / 2} \sum_{i \geq j} d_{i j}
$$

The variable $d_{i j}$ represents the shortest path length from node $v_{i}$ to node $v_{j}$.

\subsection{Mathematical Modeling}

3.2.1. Research Hypothesis. Location is a key factor affecting land value, and accessibility is an important attribute of location. Urban rail transit network investments and construction improve accessibility, create significant external effects, and promote the development of residential land and commercial land along the lines and stations $[23,46]$. When analyzing the accessibility of urban rail transit, previous studies have generally measured accessibility from two aspects based on the geographical structure of urban rail transit: the travel distance between the residence and destination (such as the city center and workplace), and the time required to travel the distance $[47,48]$. When other conditions are held constant, the land value increases if accessibility is improved and traffic costs are reduced [33].

The network characteristics reflect the accessibility of the urban rail transit network. The numbers of nodes and edges reveal the size of the urban rail transit network. The more nodes and edges of the network there are, the larger the size and coverage of the urban rail transit network are, the higher the accessibility of the city is. Improvements in accessibility generate more opportunities for the public to access social 
activities within a specific travel time or distance [49]. This may result in increased land values.

The average clustering coefficient of the Space-P model reflects the connection between the nodes in the urban rail transit network. The higher the average clustering coefficient of the network is, the tighter the connection between the nodes is. The average path length of the Space-P model shows the average number of lines needed to travel from one station to any other stations along the shortest path. The smaller the average shortest path length is, the higher the traffic accessibility of the network is expected to be.

Given this, the global characteristics of the Space-P model of the urban rail transit network, such as the number of nodes, average clustering coefficient, and average path length, reflect the accessibility of the urban rail transit network. To demonstrate the impact of urban rail transit network characteristics on land value uplift, the study tested the following hypotheses (Figure 2):

H1: the greater the number of nodes in the urban rail transit network is, the higher the prices of residential land and commercial land are

$\mathrm{H} 2$ : the larger the average clustering coefficient in the Space-P model of the urban rail transit network is, the higher the prices of residential land and commercial land are

H3: the smaller the average path length in the Space$P$ model of the urban rail transit network is, the higher the prices of residential land and commercial land are

3.2.2. Modeling the Influence of Urban Rail Transit Network Characteristics on Land Prices. Based on the semilogarithmic hedonic price model, and considering the leading effect of urban rail transit planning on land value uplift, the model assessing the influence of urban rail transit network characteristics on land prices is expressed as follows:

$$
\begin{aligned}
\ln \left(\mathrm{LP}_{i t}\right) & =\alpha+\sum_{j=1}^{J} \beta_{1 j} \cdot \mathrm{URT}_{i t j}-\text { pre } 4+\sum_{k=1}^{K} \beta_{2 k} \cdot X_{i t k}+\varepsilon, \\
i & =1,2, \ldots, M \\
t & =1,2, \ldots, T .
\end{aligned}
$$

In this expression, $\mathrm{LP}_{i t}$ is the land price for city $i$ in time $t$; $\mathrm{URT}_{i t j-\text { pre }} 4$ is the $j$ th network characteristic of city $i$ in

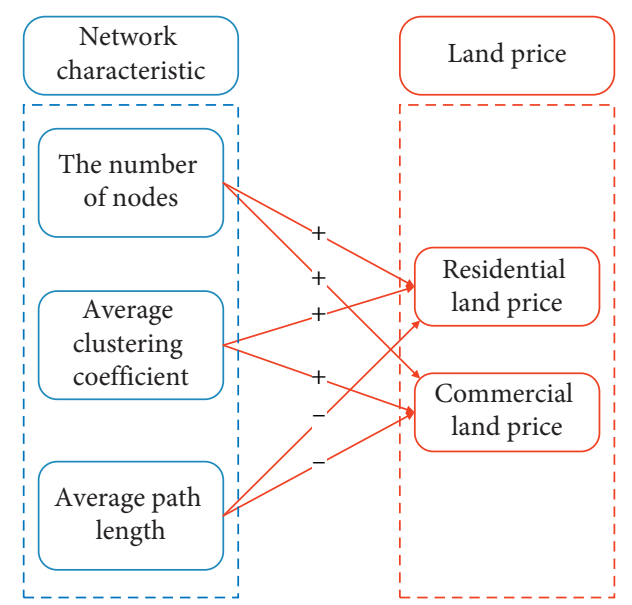

FIGURE 2: Illustration of research hypotheses to assess the influence of urban rail transit network characteristics on the land price.

time $(t+4) ; X_{i t k}$ is the $k$ th control variable of city $i$ in time $t$; $\beta_{1 j}$ is the coefficient of the $j$ th network characteristic; $\beta_{2 k}$ is the coefficient of the $k$ th control variable; $\alpha$ is the intercept term; $\varepsilon$ is the error term.

Table 1 shows the different estimation methods using the panel data model to assess the impact of urban rail transit network characteristics on land prices (Formula (4)).

In Table $1, \omega_{i t}$ is the mixed random error term, $\mu_{i}$ is the section random error term, and $v_{t}$ is the time random error term. Both $\mu_{i}$ and $v_{t}$ follow normal distributions, $W$ and $D$ are dummy variables, and

$$
\begin{aligned}
W_{i} & = \begin{cases}1, & \text { if it's in the ith cross section unit, } \quad i=2,3, \ldots, M, \\
0, & \text { other term, }\end{cases} \\
D_{t} & = \begin{cases}1, & \text { if it's in period } t, \quad t=2,3, \ldots, T, \\
0, & \text { other term. }\end{cases}
\end{aligned}
$$

A pooled model, fixed effects model, and random effects model were used to estimate the panel data model; the best model was ultimately selected using the F-test, Lagrange Multiplier Test (Breusch-Pagan), and Hausman Test.

The number of nodes $(n)$, average clustering coefficient $(c)$, and average path length $(l)$ are introduced to measure the network characteristics of the urban rail transit Space-P model. Per capita GDP and urban population density serve as control variables. By substituting formula (4), the model representing the influence of urban rail transit network characteristics on land prices is described as follows:

$$
\begin{aligned}
\ln \left(L P_{i t}\right) & =\alpha+\beta_{11} \cdot n_{i t} \text {-pre } 4+\beta_{12} \cdot c_{i t} \text {-pre } 4+\beta_{13} \cdot l_{i t} \text {-pre } 4+\beta_{21} \cdot \mathrm{GDP}_{-} \mathrm{PC}_{i t}+\beta_{22} \cdot \text { POP_PL }_{i t}+\varepsilon \\
i & =1,2, \ldots, M \\
t & =1,2, \ldots, T .
\end{aligned}
$$

In these expressions, $n_{i t}$-pre $4, c_{i t}$-pre 4 , and $l_{i t}$-pre 4 are the number of nodes, average clustering coefficient, and average path length of urban rail transit network of city $i$ in time $(t+4)$, respectively; GDP_PC $i t$ is per capita GDP of city 
TABLE 1: Estimation methods for the panel data model to assess the impact of urban rail transit network characteristics on land prices.

\begin{tabular}{|c|c|}
\hline Estimation method & Model equation \\
\hline Pooled model & $\ln \left(\mathrm{LP}_{i t}\right)=\alpha_{0}+\sum_{j=1}^{J} \beta_{1 j} \cdot \mathrm{URT}_{i t j-\text { pre }} 4+\sum_{k=1}^{K} \beta_{2 k} \cdot X_{i t k}+\varepsilon_{i t}$ \\
\hline Individual fixed effects model & $\ln \left(\mathrm{LP}_{i t}\right)=\sum_{j=1}^{J} \beta_{1 j} \cdot \mathrm{URT}_{i t j-}$ pre $4+\sum_{k=1}^{K} \beta_{2 k} \cdot X_{i t k}+\gamma_{1}+\sum_{i=2}^{M} \gamma_{i} \cdot W_{i}+\varepsilon_{i t}$ \\
\hline Time fixed effects model & $\ln \left(\mathrm{LP}_{i t}\right)=\sum_{j=1}^{J} \beta_{1 j} \cdot \mathrm{URT}_{i t j-}$ pre $4+\sum_{k=1}^{K} \beta_{2 k} \cdot X_{i t k}+\alpha_{1}+\sum_{t=2}^{T} \alpha_{t} \cdot D_{t}+\varepsilon_{i t}$ \\
\hline Individual-time fixed effects model & $\ln \left(\mathrm{LP}_{i t}\right)=\sum_{j=1}^{J} \beta_{1 j} \cdot \mathrm{URT}_{i t j-\text { pre }} 4+\sum_{k=1}^{K} \beta_{2 k} \cdot X_{i t k}+\gamma_{1}+\sum_{i=2}^{M} \gamma_{i} \cdot W_{i}+\alpha_{1}+\sum_{t=2}^{T} \alpha_{t} \cdot D_{t}+\varepsilon_{i t}$ \\
\hline Individual random effects model & $\ln \left(\mathrm{LP}_{i t}\right)=\alpha_{0}+\sum_{j=1}^{J} \beta_{1 j} \cdot \mathrm{URT}_{i t j-\operatorname{pre}} 4+\sum_{k=1}^{K} \beta_{2 k} \cdot X_{i t k}+\omega_{i t}+u_{i}$ \\
\hline Time random effects model & $\ln \left(\mathrm{LP}_{i t}\right)=\alpha_{0}+\sum_{j=1}^{J} \beta_{1 j} \cdot \mathrm{URT}_{i t j}-\operatorname{pre} 4+\sum_{k=1}^{K} \beta_{2 k} \cdot X_{i t k}+\omega_{i t}+v_{t}$ \\
\hline Individual-time random effects model & $\ln \left(\mathrm{LP}_{i t}\right)=\alpha_{0}+\sum_{j=1}^{J} \beta_{1 j} \cdot \mathrm{URT}_{i t j-\text { pre }} 4+\sum_{k=1}^{K} \beta_{2 k} \cdot X_{i t k}+\omega_{i t}+u_{i}+v_{t}$ \\
\hline
\end{tabular}

$i$ in time $t$; POP_PL $L_{i t}$ is the urban population density of city $i$ in time $t$.

\section{Empirical Analysis and Results}

\subsection{Research Scope}

4.1.1. Urban Rail Transit Network. There are many types of urban rail transit systems, including metro, light rail, monorail, maglev, automated people mover systems (APM), inner-city rapid rail, and tram. Trams are outside the scope of this study, as they are vulnerable to road traffic conditions, they are slow, and the traffic volume is relatively low. As such, the urban rail transit systems studied in this paper include metro, light rail, monorail, maglev, automated people mover systems (APM), and inner-city rapid rail.

By the end of 2019, 40 cities in the Chinese mainland had opened urban rail transit systems, with a total of 208 lines and a total of 6,736.2 kilometers in operation. This empirical study focuses on eight metropolises in China, including Beijing, Shanghai, Guangzhou, Shenzhen, Nanjing, Wuhan, Tianjin, and Chongqing. The goal was to assess the impact of network characteristics of urban rail transit planning on land value uplift from 2003 to 2022.

4.1.2. Land Value. The rent and price of land represent the currency-based land value; as such, the land price serves as the measurement index of land value for this study. Urban rail transit significantly influences residential and commercial land values; in contrast, it has little impact on industrial land values [46]. Residential and commercial land prices are generally higher than industrial land prices in the transfer market for "right to use" stateowned land in China. Therefore, the land prices in this study refer to the transfer price for residential and commercial land in the transfer market of the "right to use" state-owned land of Beijing, Shanghai, Guangzhou, Shenzhen, Nanjing, Wuhan, Tianjin, and Chongqing from 2003 to 2018.

4.2. Data Sources. The data used for this study's empirical analysis include the global characteristics of urban rail transit networks for 2003 to 2022, residential and commercial land prices for 2003 to 2018, and social and economic data for 2003 to 2018.
The information about lines and stations of urban rail transit planning from 2003 to 2022 comes mainly from each city's official urban rail transit website. The number of nodes, the average clustering coefficient, and the average path length were calculated using PAJEK. Land price data include residential and commercial land prices in Beijing, Shanghai, Guangzhou, Shenzhen, Nanjing, Wuhan, Tianjin, and Chongqing from 2003 to 2018. Due to the unbalanced distribution of land transactions in the city, the average land price cannot be directly calculated using average land transaction prices. Therefore, the level prices of residential and commercial land, published by the dynamic monitoring system of land price in China, are used to measure the average land price of relevant land types. The socioeconomic status indicators of the studied cities include per capita GDP and the population density of Beijing, Shanghai, Guangzhou, Shenzhen, Nanjing, Wuhan, Tianjin, and Chongqing from 2003 to 2018. The per capita GDP and population density data were obtained from urban statistical yearbooks of each city for the studied years.

To remove the impact of inflation or deflation, the residential land prices, commercial land prices, and per capita GDP for each city were processed through the Consumer Price Index (CPI), where the year 2003 is as the base period. The processed data are inputs for the subsequent regression analysis.

4.3. Empirical Research. Formula (5) was used to assess panel data across eight major cities in China, spanning from 2003 to 2022 . The goal was to assess the influence of urban rail transit Space-P network characteristics on residential and commercial land prices.

4.3.1. Descriptive Statistical Analysis. Table 2 lists the model variables for assessing the role of the urban rail transit Space$\mathrm{P}$ network characteristics on land value uplift. Residential land prices (LP_RESI) and commercial land prices (LP_COMM) are the explained variables in the model. The explaining variables include the number of nodes (n_pre4), average clustering coefficient (c_pre4), average path length (1_pre4), population density (POP_PL), and per capita GDP (GDP_PC). Statistical analysis was conducted to describe these variables. Table 3 shows the analysis results, including the variable unit, the sample size, mean value, standard deviation, the minimum value, and the maximum value. 
TABLe 2: Description of model variables.

\begin{tabular}{lccc}
\hline Variable category & & Variable name & Variable symbol \\
\hline \multirow{2}{*}{ Explained variable } & & Residential land price & LP_RESI \\
& & Commercial land price & LP_COMM \\
& Network & The number of nodes & n_pre4 \\
Explanatory variable & characteristic (URT) & Average clustering coefficient & c_pre4 \\
& Socioeconomic & Average path length & Population density \\
& variable $(X)$ & Per capita GDP & POP_PL \\
\hline
\end{tabular}

Table 3: Descriptive statistical analysis of model variables.

\begin{tabular}{lcccccc}
\hline Variable & Unit & Sample size & Mean value & Standard deviation & The minimum value & The maximum value \\
\hline LP_RESI & $\mathrm{RMB} / \mathrm{m}^{2}$ & 128 & 10620.00 & 10685.03 & 1393.00 & 47461.00 \\
LP_COMM & $\mathrm{RMB} / \mathrm{m}^{2}$ & 128 & 12842.00 & 9294.71 & 3295.00 & 38955.00 \\
n_pre4 & & 128 & 156.74 & 105.15 & 0.00 & 409.00 \\
c_pre4 & & 128 & 0.94 & 0.03 & 1.00 & 1.00 \\
l_pre4 & & 128 & 1.96 & 0.47 & 775.00 & 6482.00 \\
POP_PL & Person $/ \mathrm{km}^{2}$ & 128 & 2028.00 & 1400.95 & 9117.00 & 124151.00 \\
GDP_PC & RMB/person & 128 & 60497.00 & 26020.09 & \\
\hline
\end{tabular}

4.3.2. Unit Root Test for Panel Data. To avoid spurious regression, a unit root test for the panel data was introduced to assess the presence of a unit root in each sequence and to analyze the stationarity of panel data. The data includes residential and commercial land prices of each city after taking the logarithmic value from 2003 to 2018, socioeconomic data for each city from 2003 to 2018, and the network characteristics of the urban rail transit Space-P model from 2007 to 2022.

The common methods to conduct a unit root test include Levin-Lin-Chu (LLC), Im-Pesaran-Shin (IPS), Breitung, ADF-Fisher, and PP-Fisher. Based on the characteristics of the panel data in the model, the Levin-Lin-Chu (LLC), ADFFisher, and PP-Fisher were selected as the methods for the unit root test. The unit root test for panel data was conducted using Stata. Table 4 shows the results and indicates that the null hypothesis of unit root is rejected. This means that the panel data is stable.

4.3.3. Cointegration Tests for Panel Data. To test the presence of a long-term equilibrium relationship between variables, the Pedroni test and Kao test were introduced as cointegration test methods to assess the panel data of the residential and commercial land market models, respectively. Table 5 shows that the two tests indicate that the null hypothesis is rejected. In other words, there is a long-term equilibrium relationship between the variables.

4.3.4. Multicollinearity Test. Multicollinearity refers to a significant correlation between the explanatory variables of a model, which can distort estimates. To avoid this distortion, the method of variance inflation factor (VIF) calculated by $R$ was selected to test for multicollinearity. The VIF is generally greater than one. The closer VIF is to 1 , the less there is a multicollinearity problem; a higher value represents a more significant problem. If $1<\mathrm{VIF}<10$, the multicollinearity is generally not considered serious; if $10 \leq \mathrm{VIF}<100$, the multicollinearity is strong; and if VIF $\geq 100$, multicollinearity is very serious. Table 6 shows that all the variance inflation factors in this study are less than 10 . In other words, there is no significant multicollinearity among the explanatory variables of the model assessing the impact of urban rail transit network characteristics on land value uplift.

4.3.5. Heteroscedasticity Test. The classical linear regression model assumes that the random error terms have the same variance. To assess whether the model is suitable for classical linear regression, the Breusch-Pagan test was selected to test for heteroscedasticity. The results are shown in Table 7. For both the residential and commercial land market models, the $P$ values of heteroscedasticity tests are not less than 0.05 , indicating that the null hypothesis is not rejected. In other words, there are no significant heteroscedasticities in the residential and land market models.

4.3.6. Analysis of the Model Regression Results. Table 8 shows the model results representing the influence of network characteristics of the urban rail transit Space-P network on land value uplift, estimated by $R$. The F-test, Lagrange Multiplier Test (Breusch-Pagan), and Hausman Test indicate that the individual random effects model was better than other estimation methods for the residential land market model and the commercial land market model. The degrees of fit are high (the adjusted $R^{2}$ is 0.784 and 0.668 , respectively).

Some of the regression coefficients are small in Table 8, due to a difference in the magnitude of the explained and explanatory variables. To show a more accurate degree of the influences from the network characteristics (e.g., the number of nodes, average clustering coefficient, and average path length) to residential and commercial land prices, further analysis is conducted as follows. 
TABLe 4: The results of unit root test for panel data.

\begin{tabular}{lccccccc}
\hline Method & Ln (LP_RESI) & Ln (LP_COMM) & n_pre4 & c_pre4 & 1_pre4 & POP_PL & GDP_PC \\
\hline \multirow{2}{*}{ LLC } & $-2.687^{* * *}$ & $-3.643^{* * *}$ & $-3.584^{* * *}$ & $-2.907^{* * *}$ & $-2.375^{* * *}$ & $-3.812^{* * *}$ & $-2.180^{* *}$ \\
& $(0.004)$ & $(0.000)$ & $(0.000)$ & $(0.002)$ & $(0.009)$ & $(0.000)$ & $(0.015)$ \\
ADF- & $43.748^{* * *}$ & $40.964^{* * *}$ & $49.939^{* * *}$ & $40.952^{* * *}$ & $58.204^{* * *}$ & $42.562^{* * *}$ & $34.343^{* * *}$ \\
Fisher & $(0.000)$ & $(0.001)$ & $(0.000)$ & $(0.001)$ & $(0.000)$ & $(0.000)$ & $(0.005)$ \\
PP-Fisher & $32.573^{* * *}$ & $91.634^{* * *}$ & $62.262^{* * *}$ & $32.835^{* * *}$ & $37.441^{* * *}$ & $65.552^{* * *}$ & $35.242^{* * *}$ \\
& $(0.008)$ & $(0.000)$ & $(0.000)$ & $(0.008)$ & $(0.002)$ & $(0.000)$ & $(0.004)$ \\
\hline
\end{tabular}

$P$ values in parentheses; ${ }^{*} p<0.10,{ }^{* *} p<0.05$, and ${ }^{* * *} p<0.01$.

TABLE 5: The results of the cointegration test for panel data.

\begin{tabular}{lccc}
\hline Method & & Residential land market model & Commercial land market model \\
\hline \multirow{3}{*}{ Pedroni test } & Modified Phillips-Perron $t$ & $4.690^{* * *}(0.000)$ & $4.721^{* * *}(0.000)$ \\
& Phillips-Perron $t$ & $-6.726^{* * *}(0.000)$ & $-8.806^{* * *}(0.000)$ \\
\hline \multirow{3}{*}{ Kao test } & Augmented Dickey-Fuller $t$ & $-5.963^{* * *}(0.000)$ & $-8.028^{* * *}(0.000)$ \\
& Modified Dickey-Fuller $t$ & $2.151^{* *}(0.016)$ & $2.082^{* *}(0.019)$ \\
& Dickey-Fuller $t$ & $2.631^{* * *}(0.004)$ & $2.573^{* * *}(0.005)$ \\
\hline
\end{tabular}

$P$ values in parentheses; ${ }^{*} p<0.10,{ }^{* *} p<0.05$, and ${ }^{* * *} p<0.01$.

TABLE 6: The results of multicollinearity test.

\begin{tabular}{lccccc}
\hline Variable & n_pre4 & c_pre4 & l_pre4 & POP_PL & GDP_PC \\
\hline VIF & 5.172 & 6.751 & 3.552 & 1.797 & 2.271 \\
\hline
\end{tabular}

TABLE 7: The results of the heteroscedasticity test.

\begin{tabular}{lcc}
\hline Model & BP & $P$ value \\
\hline Residential land market model & 8.663 & 0.123 \\
Commercial land market model & 2.289 & 0.808 \\
\hline
\end{tabular}

TABLE 8: The results of the regression model.

\begin{tabular}{lcc}
\hline & Residential land market model & Commercial land market model \\
\hline Explained variable & $\ln \left(\mathrm{LP} \_\right.$RESI) & ln (LP_COMM) \\
Intercept & $1.07 e+00<0.526>$ & $1.04 e+00<0.502>$ \\
n_pre4 & $6.08 e-03^{* * *}<7.379>$ & $3.46 e-03^{* * *}<4.002>$ \\
c_pre4 & $6.82 e+00^{* * *}<3.431>$ & $7.37 e+00^{* * *}<3.651>$ \\
l_pre4 & $-2.83 e-01^{* * *}<-2.669>$ & $-2.70 e-01^{* *}<-2.500>$ \\
POP_PL & $2.07 e-04^{* * *}<3.237>$ & $2.29 e-04^{* * *}<3.279>$ \\
GDP_PC & $8.50 e-06^{* * *}<2.662>$ & $1.22 e-05^{* * *}<3.605>$ \\
Sample size & 128 & 128 \\
The adjusted $R^{2}$ & 0.784 & 0.668 \\
Model type & Individual random effects model & Individual random effects model \\
Model estimation method & Generalized least squares method (GLS) & Generalized least squares method (GLS) \\
\hline Z-statistics in angular brackets; ${ }^{*} p<0.10,{ }^{* *} p<0.05$, and ${ }^{* * *} p<0.01$. &
\end{tabular}

The influence of urban rail transit network characteristics on land value uplift was modeled as a semilogarithm. The model is described in formula (4).

$$
\ln \left(\mathrm{LP}_{i t}\right)=\alpha+\sum_{j=1}^{J} \beta_{1 j} \cdot \mathrm{URT}_{i t j-} \text { pre } 4+\sum_{k=1}^{K} \beta_{2 k} \cdot X_{i t k}+\varepsilon .
$$

If the other explanatory variables are held constant, by changing the $j$ th network characteristic, formula (4) can be transformed into

$$
\Delta \ln (\mathrm{LP})=\beta_{1 j} \cdot \Delta \mathrm{URT}_{j}-\text { pre } 4,
$$

where $\mathrm{LP}^{\prime}$ denotes the land price after the change. If the $j$ th network characteristic increases by $\varphi$, then, 
TABLE 9: The results of the hypothesis testing.

\begin{tabular}{lcccccc}
\hline Model & Explanatory variable & Correlation & $\varphi$ & Inc(LP) & Dec(LP) & Hypothesis testing results \\
\hline \multirow{3}{*}{ Residential land market model } & n_pre4 & Positive & 10 & 6.269 & & H1 is validated \\
& c_pre4 & Positive & 0.01 & 7.058 & & H2 is validated \\
& 1_pre4 & Negative & 0.1 & & 2.790 & H3 is validated \\
\hline \multirow{3}{*}{ Commercial land market model } & n_pre4 & Positive & 10 & 3.521 & & H1 is validated \\
& c_pre4 & Positive & 0.01 & 7.648 & H2 is validated & H3 is validated \\
\hline
\end{tabular}

$$
\frac{\mathrm{LP}^{\prime}}{\mathrm{LP}}=e^{\beta_{1 j} \cdot \varphi}
$$

That is, if the $j$ th network characteristic increases by $\varphi$, the land price will increase by Inc(LP)\%,

$$
\operatorname{Inc}(\mathrm{LP}) \%=\left(e^{\beta_{1 j} \cdot \varphi}-1\right) \cdot 100 \% \text {, }
$$

or decrease by Dec(LP)\%,

$$
\operatorname{Dec}(\mathrm{LP}) \%=\left(1-e^{\beta_{1 j} \cdot \varphi}\right) \cdot 100 \% .
$$

As a result of applying formulae (8)-(11) and the information in Table 8, Table 9 shows the impact on land value uplift based on urban rail transit network characteristics and the hypothesis testing results.

Tables 8 and 9 show that the number of nodes of the urban rail transit Space-P network four years in the future is significantly positively correlated with residential land price and commercial land price. This supports hypothesis $\mathrm{H} 1$. However, the correlation coefficient in the residential land market model is higher compared to the commercial land market model. When other conditions are constant, residential land and commercial land prices increase by $6.269 \%$ and $3.521 \%$, respectively, for a new line with ten additional nodes in the Space-P model of the urban rail transit network. In other words, the addition of new lines and stations will cause land value uplift, and the influence degree is much higher on residential land prices than commercial land prices.

There is a significant positive correlation between the average clustering coefficient of the urban rail transit Space-P network four years in the future and land prices in residential and commercial land markets. This finding supports hypothesis H2. However, the correlation coefficient is higher in the commercial land market model compared to the residential land market. When other conditions are constant, for every 0.01 increase in the average clustering coefficient of the urban rail transit Space-P network, the residential land price increases by $7.058 \%$ and the commercial land price increases by $7.648 \%$. The larger the average clustering coefficient is, the tighter the network connection is. That is to say, an urban rail transit network with tighter connections will cause land value uplift, and the impact of the average clustering coefficient on the prices of commercial land is slightly higher than that on the prices of residential land.

There is a significant negative correlation between the average path length of the urban rail transit Space- $P$ network four years in the future and residential and commercial land prices. This finding supports hypothesis H3. However, the correlation coefficient is higher in the residential land market model compared to the commercial land market model. When other conditions are constant, the average path length increases by 0.1 , the residential land price decreases by $2.790 \%$, and the commercial land price decreases by $2.664 \%$. On the contrary, if the average path length of urban rail transit decreases, passengers will have more convenient travel with fewer transfers. As a result, land prices in residential and commercial land markets will increase, and the influence degree on the prices of residential land is slightly higher than that of commercial land.

\section{Discussion}

Urban rail transit can create a land value uplift for residential and commercial land, with the influence felt in advance of construction. This finding was consistent with other studies $[22,24]$. However, similar to other research, these studies are based on the geographical structure of urban rail transit. By conceptualizing the urban rail transit system as a complex network, this study analyzed the impact of urban rail transit on land value uplift based on the network structure at a macro level.

This study introduced the number of nodes, the average clustering coefficient, and the average path length to measure the global network characteristics of the urban rail transit Space-P model. The study found that both the number of nodes and the average clustering coefficient are positively correlated with the prices of residential and commercial land; however, there is a negative correlation between the average path length and the land prices.

The number of nodes is an important factor driving the construction and operating cost of the urban rail transit network [50]. As the urban rail transit network is developed, the number of stations increases and the network scale expands. Due to high construction costs, urban rail transit generates large external benefits but can aggravate the debt burden of the local government. Therefore, excessive plans, overconcentration of construction, and funding shortages should be avoided when planning an urban rail transit network.

The average clustering coefficient reflects the connection of the network: the larger the average clustering coefficient is, the tighter the network connection is. The average shortest path length of the urban rail transit network refers to the average number of routes that any two stations in the network need to take to reach each other, based on the shortest path. The land value uplift effect of the urban rail 
transit network with a large average clustering coefficient and small average path length is significant.

To sum up, controlling the scale and development rhythm of urban rail transit and formulating a scientific and reasonable urban rail transit development plan are beneficial to improve the development quality of the urban rail transit network. In the setting of new lines and stations, the network with a larger average clustering coefficient and a smaller average path length is usually more attractive to passengers and more competitive. Urban rail transit can increase the land price. Recycling the increment of land value caused by urban rail transit is a significant financing mode for the construction of the urban rail transit network.

\section{Conclusions and Implications}

The urban rail transit network is a typical complex network with growth properties. However, few studies have examined the relationships between urban rail transit network characteristics and land value uplift using complex network theory at the macro level. This means that the externalities of urban rail transit have not been fully elaborated, and the relationship between urban rail transit and land value uplift has not been thoroughly discussed. To fill these gaps, this study constructed the Space-P model of the urban rail transit network, based on complex network theory, and demonstrated the impact of the network's characteristics on land value uplift at a macro and dynamic level.

The results of this study show that the urban rail transit network has a leading effect on land value uplift. In the urban rail transit Space-P network, four years in the future, if the number of network nodes and the average clustering coefficient are larger, with a smaller average shortest path length, the prices of residential and commercial land are higher, if other conditions are constant. The number of network nodes is an important factor impacting the construction and operation management cost of the urban rail transit network [50]. In other words, the greater the number of network nodes is, the higher the construction and operation management cost of the urban rail transit network is expected to be. Controlling the scale, anticipating the development rhythm, and formulating a scientific and reasonable planning approach support improvements in the development quality of the urban rail transit network.

When the network size is the same, small-world networks usually have a larger clustering coefficient and smaller average shortest path length compared to networks which do not have small-world characteristics [51]. The stronger the small-world characteristics of the Space-P model of the urban rail transit network are, the shorter the average distance between any two stations in the network is and the higher the network accessibility is likely to be. When designing new lines and stations of an urban rail transit network, designers should enhance the small-world characteristics of the Space-P network. Meanwhile, the network will likely have a large average clustering coefficient and a small average path length, improving the competitiveness of the urban rail transit network.
Value capture is an effective way to fund an urban rail transit system. It supports improvements in the investment and financing mode of urban rail transit systems and promotes the sustainable development of the urban rail transit network. The results of this study can be applied to better anticipate the effect of different network characteristics on land value uplift with respect to urban rail transit networks and provide theoretical insights related to value capture.

\section{Data Availability}

The data used in this paper are available from the corresponding author upon request.

\section{Conflicts of Interest}

The authors declare that there are no conflicts of interest regarding the publication of this paper.

\section{Acknowledgments}

This research was supported by the general program of the National Social Science Foundation of China (19BGL274).

\section{References}

[1] H. Suzuki, R. Cervero, and K. Iuchi, Transforming Cities with Transit: Transit and Land-Use Integration for Sustainable Urban Development, The World Bank, Washington DC, USA, 2013.

[2] J. J. Smith and T. A. Gihring, "Financing transit systems through value capture," American Journal of Economics and Sociology, vol. 65, no. 3, pp. 751-786, 2006.

[3] E. A. Hopkins, "The influence of public transportation on housing values," International Journal of Sustainable Development \& World Ecology, vol. 25, no. 3, pp. 206-215, 2018.

[4] K. Credit, "Transit-oriented economic development: the impact of light rail on new business starts in the Phoenix, AZ Region, USA," Urban Studies, vol. 55, no. 13, pp. 2838-2862, 2018.

[5] Y. Kaneko, T. Nakagawa, V. K. Phun, and H. Kato, "Impacts of urban railway investment on regional economies: evidence from Tokyo using spatial difference-in-differences analysis," Transportation Research Record: Journal of the Transportation Research Board, vol. 2673, no. 10, pp. 129-140, 2019.

[6] L. H. Atuesta, J. E. Ibarra-Olivo, N. Lozano-Gracia, and U. Deichmann, "Access to employment and property values in Mexico," Regional Science and Urban Economics, vol. 70, pp. 142-154, 2018.

[7] C.-D. Kang, "Spatial access to metro transit villages and housing prices in Seoul, Korea," Journal of Urban Planning and Development, vol. 145, no. 3, Article ID 05019010, 2019.

[8] H. Li, Y. D. Wei, Y. Wu, and G. Tian, "Analyzing housing prices in Shanghai with open data: amenity, accessibility and urban structure," Cities, vol. 91, pp. 165-179, 2019.

[9] R. Hu, "The impact of rail transit on the distribution of new housing projects in Beijing," Urban Studies, vol. 54, no. 8, pp. 1867-1886, 2017.

[10] X. Liang, Y. Liu, T. Qiu, Y. Jing, and F. Fang, "The effects of locational factors on the housing prices of residential communities: the case of Ningbo, China," Habitat International, vol. 81, pp. 1-11, 2018. 
[11] S. Chen, D. Zhuang, and H. Zhang, "GIS-based spatial autocorrelation analysis of housing prices oriented towards a view of spatiotemporal homogeneity and nonstationarity: a case study of Guangzhou, China," Complexity, vol. 2020, Article ID 1079024, 16 pages, 2020.

[12] M. F. Dziauddin, N. Powe, and S. Alvanides, "Estimating the effects of light rail transit (LRT) system on residential property values using geographically weighted regression (GWR)," Applied Spatial Analysis and Policy, vol. 8, no. 1, pp. 1-25, 2015.

[13] S. Mathur, "Impact of heavy-rail-based rapid transit on house prices: evidence from the fremont, CA, warm springs BART extension project," Journal of Planning Education and Research, pp. 1-20, 2020.

[14] J. Camins-Esakov and D. Vandegrift, "Impact of a light rail extension on residential property values," Research in Transportation Economics, vol. 67, pp. 11-18, 2018.

[15] R. Cervero and M. Duncan, "Transit's value-added effects: light and commuter rail services and commercial land values," Transportation Research Record: Journal of the Transportation Research Board, vol. 1805, no. 1, pp. 8-15, 2002.

[16] E. Guerra, R. Cervero, and D. Tischler, "Half-mile circle," Transportation Research Record: Journal of the Transportation Research Board, vol. 2276, no. 1, pp. 101-109, 2012.

[17] C. Mulley, C.-H. Tsai, and L. Ma, "Does residential property price benefit from light rail in Sydney?" Research in Transportation Economics, vol. 67, pp. 3-10, 2018.

[18] D. G. Chatman, N. K. Tulach, and K. Kim, "Evaluating the economic impacts of light rail by measuring home appreciation," Urban Studies, vol. 49, no. 3, pp. 467-487, 2012.

[19] M. F. Dziauddin, "Estimating land value uplift around light rail transit stations in Greater Kuala Lumpur: an empirical study based on geographically weighted regression (GWR)," Research in Transportation Economics, vol. 74, pp. 10-20, 2019.

[20] A. Forouhar and M. Hasankhani, "The effect of Tehran metro rail system on residential property values: a comparative analysis between high-income and low-income neighbourhoods," Urban Studies, vol. 55, no. 16, pp. 3503-3524, 2018.

[21] A. Forouhar, "Estimating the impact of metro rail stations on residential property values: evidence from Tehran," Public Transport, vol. 8, no. 3, pp. 427-451, 2016.

[22] S. Kim and J. Byun, "Identifying spatiotemporally-varying effects of a newly built subway line on land price: difference and correlation between commercial and residential uses," International Journal of Sustainable Transportation, vol. 15, no. 5, pp. 364-374, 2020.

[23] S. Bhattacharjee and A. R. Goetz, "The rail transit system and land use change in the Denver metro region," Journal of Transport Geography, vol. 54, pp. 440-450, 2016.

[24] Q. Pan, "The impacts of light rail on residential property values in a non-zoning city: a new test on the Houston metro rail transit line," Journal of Transport and Land Use, vol. 12, no. 1, pp. 241-264, 2019.

[25] K. Seo, D. Salon, M. Kuby, and A. Golub, "Hedonic modeling of commercial property values: distance decay from the links and nodes of rail and highway infrastructure," Transportation, vol. 46, no. 3, pp. 859-882, 2019.

[26] H. Yu, H. Pang, and M. Zhang, "Value-added effects of transit-oriented development: the impact of urban rail on commercial property values with consideration of spatial heterogeneity," Papers in Regional Science, vol. 97, no. 4, pp. 1375-1396, 2018.
[27] K. Ko and X. Cao, "The impact of Hiawatha light rail on commercial and industrial property values in Minneapolis," Journal of Public Transportation, vol. 16, no. 1, pp. 47-66, 2013.

[28] G. Debrezion, E. Pels, and P. Rietveld, "The impact of railway stations on residential and commercial property value: a meta-analysis," The Journal of Real Estate Finance and Economics, vol. 35, no. 2, pp. 161-180, 2007.

[29] X. Cao and D. Porter-Nelson, "Real estate development in anticipation of the green line light rail transit in St. Paul," Transport Policy, vol. 51, pp. 24-32, 2016.

[30] B. T. H. Yen, C. Mulley, H. Shearer, and M. Burke, "Announcement, construction or delivery: when does value uplift occur for residential properties? evidence from the gold coast light rail system in Australia," Land Use Policy, vol. 73, pp. 412-422, 2018.

[31] M. Diao, D. Leonard, and T. F. Sing, "Spatial-difference-indifferences models for impact of new mass rapid transit line on private housing values," Regional Science and Urban Economics, vol. 67, pp. 64-77, 2017.

[32] S. Zheng, X. Hu, B. Zhang et al., "Urban rail transit's valueadded capture:from theory to reality," Urban Development Studies, vol. 021, no. 002, pp. 35-41, 2014.

[33] W. Alonso, Location and Land Use: Toward a General Theory of Land Rent, Harvard University Press, Cambridge, UK, 1964.

[34] R. F. Muth, Cities and Housing, The University of Chicago Press, Chicago, IL, USA, 1969.

[35] E. S. Mills, Studies in the Structure of the Urban Economy, Johns Hopkins Press, Baltimore, MD, USA, 1972.

[36] H. George, Progress and Poverty, OUP Oxford, Oxford, UK, 1879.

[37] J. Sun, T. Chen, Z. Cheng, C. C. Wang, and X. Ning, "A financing mode of urban rail transit based on land value capture: a case study in Wuhan City," Transport Policy, vol. 57, pp. 59-67, 2017.

[38] H. W. Batt, "Value capture as a policy tool in transportation economics: an exploration in public finance in the tradition of Henry George," American Journal of Economics and Sociology, vol. 60, no. 1, pp. 193-228, 2001.

[39] H. Du and C. Mulley, "The short-term land value impacts of urban rail transit: quantitative evidence from Sunderland, UK," Land Use Policy, vol. 24, no. 1, pp. 223-233, 2007.

[40] C. Pettit, Y. Shi, H. Han et al., "A new toolkit for land value analysis and scenario planning," Environment and Planning B-Urban Analytics and City Science, vol. 47, no. 8, pp. 1-18, 2020.

[41] M. Brown-Luthango, "Capturing land value increment to finance infrastructure investment-possibilities for South Africa," Urban Forum, vol. 22, no. 1, pp. 37-52, 2011.

[42] F. Medda, "Land value capture finance for transport accessibility: a review," Journal of Transport Geography, vol. 25, pp. 154-161, 2012.

[43] J. McIntosh, P. Newman, R. Trubka et al., "Framework for land value capture from investments in transit in car-dependent cities," Journal of Transport and Land Use, vol. 10, no. 1, pp. 155-185, 2017.

[44] J. Shi, S. Wen, X. Zhao, and G. Wu, "Sustainable development of urban rail transit networks: a vulnerability perspective," Sustainability, vol. 11, no. 5, p. 1335, 2019.

[45] A. A. De Bona, K. V. O. Fonseca, M. O. Rosa, R. Lüders, and M. R. B. S. Delgado, "Analysis of public bus transportation of a Brazilian city based on the theory of complex networks using 
the P-space," Mathematical Problems in Engineering, vol. 2016, Article ID 3898762, 12 pages, 2016.

[46] C. D. Higgins and P. S. Kanaroglou, "Forty years of modelling rapid transit's land value uplift in North America: moving beyond the tip of the iceberg," Transport Reviews, vol. 36, no. 5, pp. 610-634, 2016.

[47] S. Farber and L. Fu, "Dynamic public transit accessibility using travel time cubes: comparing the effects of infrastructure (dis) investments over time," Computers, Environment and Urban Systems, vol. 62, pp. 30-40, 2017.

[48] M. Diao, "Selectivity, spatial autocorrelation and the valuation of transit accessibility," Urban Studies, vol. 52, no. 1, pp. 159-177, 2015.

[49] K. Kelobonye, G. McCarney, J. Xia, M. S. H. Swapan, F. Mao, and $\mathrm{H}$. Zhou, "Relative accessibility analysis for key land uses: a spatial equity perspective," Journal of Transport Geography, vol. 75, pp. 82-93, 2019.

[50] M. E. J. Newman, Networks: An Introduction, Publishing House of Electronics Industry, Beijing, China, 2014.

[51] D. J. Watts and S. H. Strogatz, "Collective dynamics of 'smallworld' networks," Nature, vol. 393, no. 6684, pp. 440-442, 1998. 